\title{
Self Efficacy and Collective Efficacy Beliefs of Teachers for Children with Autism
}

\author{
Evelina Dimopoulou \\ Brunel University, London, UK
}

\begin{abstract}
Researchers have sought to define teacher efficacy, and done so based on work conducted in the 1970s by the RAND organisation and also Bandura's Social Cognitive Theory. Efficacy the belief in one's capabilities to organize and execute the courses of action required to manage prospective situations. Collective efficacy refers to the judgment of teachers in a school that the faculty as a whole can organise and execute the courses of action required to have a positive effect on students. Self efficacy (SE) and collective efficacy (CE) beliefs seem to be very closely linked to childrens' progress. This study seeks to shed light on self efficacy and collective efficacy beliefs of teachers' for children with autism in autism schools across the UK. Teachers from 137 schools for children with autism across UK will be asked to complete and online survey consisting of three questionnaires on demographic, self efficacy and collective efficacy beliefs.
\end{abstract}

Keywords: self efficacy, collective efficacy, autism, teachers

\section{Introduction}

Social cognitive theory posits that an individual's behaviour is primarily learned through his or her observation of others as well as through interaction with his or her environment. Thus it is instructive to examine reciprocal relationships between school context (environment) and teacher efficacy beliefs (personal factors) [24].

Teachers' efficacy describes how much a teacher believes he or she can effectively complete the tasks that teaching requires, so that children acquire the skills required for learning. Teaching efficacy, the equivalent to Bandura's outcome expectation, is the teachers' belief that students can be taught despite external factors, such as their family environment [23].

Self-efficacy beliefs would be teachers' evaluation of their abilities to bring about positive student change [23]. However, low teacher efficacy leads to low student efficacy and low academic achievement, which in turn leads to further declines in teacher efficacy [16].

Along with the construct of teachers' efficacy, collective efficacy beliefs developed in order to explore a group's perceptions of their capabilities to complete the tasks that teaching requires, so that children acquire the skills required for learning.
Bandura [16] argued that one powerful construct that varies greatly among schools that is systematically associated with student achievement is the collective efficacy of teachers within a school. Goddard, Hoy, and Woolfolk-Hoy [27] did find a significant relationship between student achievement and collective efficacy beliefs. Also, Goddard and Goddard [26] assumed that when teachers as a group in a school believe that the staff as a whole can be successful, they will be more likely to persist in their own personal efforts to achieve such success. From an organisational perspective, collective teacher efficacy may help to explain the differential effect that schools have on student achievement. Collective teacher efficacy, therefore, has the potential to contribute to our understanding of how schools differ in the attainment of their most important objective the education of [27].

Children with autism have difficulties in the areas of language and communication, social development and creative imaginations. The symptoms range from mild to severe. Children with autism require specialist education and skilled practitioners. Educating students with autism presents teachers with significant instructional challenges [45].

Educational reform over the last two decades has meant that teachers play an increasingly prominent role in many aspects of the care and management as well as the education of their pupils [31]. It is well established that teachers' expectations about students with learning disabilities will affect their instructional goals and methods [35]. Schools for children with autism may choose to follow a particular approach for teaching their children e.g. Applied Behavioural Analysis (ABA), Treatment and Education of Autistic and Communication related handicapped Children (TEACCH), Sensory Integration, Floor time Therapy etc. or schools may use a mixture of those. Teacher training in regards to these methods varies both in term of depth and length. This study will seek to reveal relationships amongst SE, CE, methods and training.

\section{Social Cognitive Theory}

Theories must accurately demonstrate predictive power. They must accurately identify the determinants of human behaviour as well as the intervening mechanisms responsible for the changes [16]. Social Cognitive Theory of human functioning was developed by Bandura in the mid-1980s in order to explain how individuals develop and how the ways human behave is interlinked with their self and 
the influences they receive by the environment. It provides a framework for understanding, predicting, and changing human behaviour. Social cognitive theory [16] posits that an individual's behaviour is primarily learned through his or her observation of others as well as through interaction with his or her environment.

Social cognitive theory stemmed out of the work by Miller and Dollard in 1941 when they proposed the social learning theory. They asserted that individuals would learn behaviour through observing others if they were motivated to learn this particular behaviour. In other words, the behaviour they would want to learn would be related to a favourable outcome. By imitating these observed actions the individual observer would solidify that learned action and would be rewarded with positive reinforcement. Later in 1963 Bandura and Walters developed the social learning theory further including the principles of observational learning and vicarious reinforcement.

The basic principles of Social Cognitive Theory are that: i)Learning can occur by observing the behaviours of others as well as the outcomes of those behaviours Ii)Learning can occur without change in behaviour ii)The consequences on behaviour affect learning ii)Cognition affects learning

According to Bandura [12] and in unlike preceding theories all learning phenomena resulting from direct experience occur on a vicarious basis by observing other people's behaviour and its consequences on them. In other words social learning theory supports that learning occurs through a number of processes: symbolic, vicarious and self-regulatory which hold a prominent role in the acquisition of new knowledge and behaviours. Symbolic Through verbal and imagined symbols people process preserve experiences in representational forms. Through the medium symbols people can solve problems without having to enact all the various solutions. The capability for intentional action is rooted in symbolic activity. Vicarious Bandura [12] sees modeling as an indispensible aspect of learning. By observing others people are able to see behaviours and their consequences. Self regulatory Social learning theory recognises self regulatory capabilities as a prominent component of learning. By arranging environmental inducements, generating cognitive supports, ad producing consequences for their own actions, people are able to exercise some measure of control over their own behaviour. Learning through modeling.

In social learning theory modeling holds a conspicuous position in the way people learn. By observing others one forms an idea of how new behaviours are performed, and on later occasions this coded information serves as a guide for action [12]. Through modeling people acquire symbolic representations which, as mentioned earlier, enable future intentional actions

There are four defined processes in observational learning: Attention, Retention, Motor production and Motivational processes.

\subsection{Reciprocal Determinism - Triadic reciprocal causation}

From the social learning perspective, psychological functioning is a continuous reciprocal interaction between personal, behavioural and environmental determinants [12].

The environment is not a monolithic entity. Social cognitive theory distinguishes between three types of environmental structures [16]. They include the imposed environment, selected environment, and constructed environment. These different environmental structures represent gradations of changeability requiring the exercise of differing scope and focus of personal agency.

As individuals, classroom teachers proactively lead their lives and base their actions in relation to these three dimensions of social cognitive theory. The term reciprocal indicates that action is given and received by each subject to whilst determinism indicates the production of effects. Because of the varied nature of the interacting influences within this triad relationship, different conditions can produce or lead to different effects. The elements/sources 'behaviour' and 'environment' can extend to include various aspects of the schools environment. Teachers are being influenced by their students' behaviour, by the way their colleagues or senior managers conduct themselves, by the attitudes of parents and other professionals and individuals involved in every day school life.

Bandura [10] advanced a view of human functioning that accords a central role to cognitive, vicarious, self-regulatory, and self-reflective processes in human adaptation and change. People are viewed as self-organizing, proactive, selfreflecting and self-regulating rather than as reactive organisms shaped and shepherded by environmental forces or driven by concealed inner impulses. From this theoretical perspective, human functioning is viewed as the product of a dynamic interplay of personal, behavioral, and environmental influences.” 


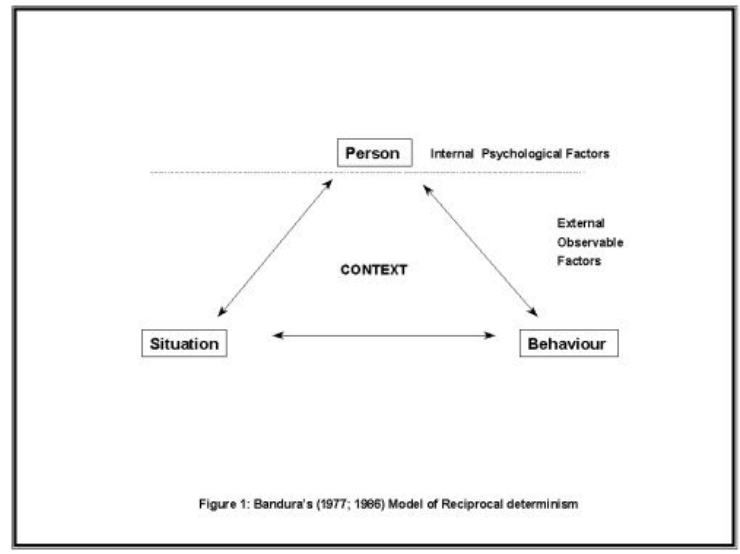

Figure 1: Social cognitive theory postulates that human functioning is determined by (a) personal factors in the form of cognition, affect, and biological events, (b) behavior, and (c) environmental influences.

It is useful to look into the particular way the pairs within the triad have an effect on each other.

\section{Teachers' Efficacy and Collective Efficacy}

Both teacher efficacy and collective efficacy have their roots in Albert Bandura's (1986) social cognitive theory, which posits that humans have control over their lives through agentive actions [12], [16]. Goddard, Hoy, and Hoy [27] posit: "Social cognitive theory is employed to explain that the choices teachers make, the ways in which they exercise personal agency, are strongly influenced by collective efficacy beliefs." Thus, an important but overlooked question (which) concerns the nested association between these two influential types of beliefs" [25] in the field of education. Additionally results from Goddard and Goddard [26] treating collective efficacy and teacher efficacy separate constructs but positively and strongly related.

Bandura [17] raised the disputable duality inappropriately equates self-efficacy with selfcentered individualism feeding selfishness, and then pits it against communal attachments and civic responsibility. A sense of efficacy does not necessarily exalt the self or spawn an individualistic lifestyle, identity, or morality that slights collective welfare.

\section{Self - Efficacy}

Central to the exercise of control is sense of selfefficacy or "beliefs in one's capabilities to organize anti execute it course of action required to produce a given attainment” [16]. Self-efficacy has to do with self-perception of competence rather than actual level of competence. Self efficacy theory is based on the principal assumption that psychological procedures, whatever their form, serve as means of creating and strengthening expectations of personal efficacy [16]. Self-efficacy theory maintains that all processes of psychological change operate through the alteration of the individual's sense of personal mastery or efficacy [16].

In the Social Cognitive Theory Bandura illustrated the notion of agent causality. Central to the exercise of control is the sense of self-efficacy or the "beliefs in one's capabilities to organise and execute a course of action required producing a given attainment” [16]. Bandura [12], [16] presented self-efficacy as a mechanism of behavioural change and self-regulation in his social cognitive theory. The organisation and execution of certain actions involves a thinking process that individuals as agents perform prior to their activities.

Efficacy beliefs begin to form in early childhood as children deal with a wide variety of experiences, tasks, and situations. However, the growth of selfefficacy does not end during youth, but continues to evolve throughout life as people acquire new skills, experiences, and understanding [7]. In 1977 in his book Social Learning Theory Bandura defined four sources of efficacy expectations: Performance accomplishments, Vicarious Experience, Verbal Persuasion and Emotional Arousal (see Figure 2). In 1997 Bandura [16] presented an amended list of principal sources of information contributing to Self efficacy beliefs:

- Self-efficacy is the idea that people decide how to behave based more on their belief in their own capabilities of accomplishment rather than in their knowledge or skills [39]. Bandura [6] clarified that self-efficacy is concerned not with the skills one has but with the capacity of what one can do with whatever skills one possesses. Bandura [16] proposed that efficacy beliefs were powerful predictors of behavior because they were ultimately self-referent in nature and directed toward specific tasks. The predictive power of efficacy has generally been borne out in research, especially when efficacy beliefs are measured concerning specific tasks [38]. Individuals who have the proclivity that they will be successful on a given task are more likely to be so because they take on challenging goals, work hard to achieve them, persevere despite setbacks and manage emotional states [43].Still, self-efficacy is helps determine our life choices, it motivates us, and it helps us deal with failures and setbacks in life [14].

- Self-efficacy has to do with self-perception of competence rather than actual level of competence. This is an important distinction, because people regularly overestimate or underestimate their actual abilities, and these estimations may have consequences for the courses of action they choose to pursue or the 
effort they exert in those pursuits [49]. Perceived self-efficacy occupies a pivotal role in the causal structure of social cognitive theory because efficacy beliefs affect adaptation and change not only in their own right, but through their impact on other determinants [17]. Amongst the types of thoughts that affect action, none is more central or pervasive than people's judgments of their capabilities to deal effectively with different realities [10].The stronger the instilled sense of coping self- efficacy, the bolder the behaviour [10].

- Self efficacy theory acknowledges the diversity of human capabilities and it therefore treats the efficacy system not as an omnibus trait but as a differentiated set of self-beliefs linked to distinct realms of functioning [16]. Efficacy beliefs do not only differ in terms of domains and contexts; they are working and living 'organisms' which are continually shaped as people change ideas, emotional states and circumstances. Since people are unique units with their own set of characteristics, abilities and cognitive mechanisms; different people with similar skills, or the same person under different circumstances, may perform poorly, adequately, or extraordinarily, depending on fluctuations in their belief of personal efficacy [10].

A common argument in social cognitive theory is the discrimination between efficacy and outcome expectations. Outcome expectancy is defined as a person's estimate that a given behaviour will lead to certain outcomes. An efficacy expectation is the conviction that one can successfully execute the behaviour required to produce an outcome [12] (see Figure 1)

Efficacy expectation is the individual's conviction that he or she can orchestrate the necessary actions to perform a given task, while outcome expectancy is the individual's estimate of the likely consequences of performing that task at the expected level of competence [6]. The efficacy expectation refers to the individual's the ability to organise and execute the actions necessary to accomplish a specific task at a desired level. However, the outcome expectation is concerned with the consequence of the performance. Efficacy expectations determine how much effort people will expend, and how long they will persist in the face of obstacles and aversive experiences [12].In this conceptual system, expectations of personal mastery affect both initiation and persistence of coping behaviour [12].

The preceding analysis of how perceived selfefficacy influences performance is not meant to imply that expectation is the sole determinant of behaviour. Expectation alone will not produce desired performance if the component capabilities are lacking [12]. Efficacy expectations differ in magnitude, generality and strength. This means that individuals develop different efficacy expectations based on the difficulty of tasks they are faced with, the spectrum they feel capable of applying their skills as well as the strength of their expectations in mastering the tasks. Discrepancies between efficacy expectations and performance are most likely to arise under conditions in which situational and task factors are ambiguous. When performance requirements are ill-defined, people who underestimate the situational demands will display positive discrepancies between self-efficacy and performance attainments [12].

Another important distinction is between perceived self efficacy and self esteem. The first is concerned with judgements of personal capability, whereas the second is concerned with judgement of self worth [16]. Also, self esteem reflects a person's overall evaluation or appraisal of his or her own worth however self efficacy is task specific. One may feel highly efficacious to perform an action but they may have a low belief in their capabilities to do something else. According to [38],there exists a mis measurement of self-efficacy when efficacy beliefs are not tailored to critical tasks. The judgment of self-efficacy is task and domain specific; therefore, globally defined self-efficacy assessments weaken the effects of self-efficacy [16]. Bandura pointed out the necessity of specific assessment for self-efficacy construct and its correspondence with the designated task in order to increase the prediction of academic outcomes.

The rapid pace of informational, social, and technological change is placing a premium on personal efficacy for self-development and selfrenewal throughout the life course [17]. Good selfregulators expand their knowledge and cognitive competencies; poor self-regulators fall behind [60]. Self-regulation is also becoming a key factor in occupational life.

Efficacious people are quick to take advantage of opportunity structures and figure out ways to circumvent institutional constraints or change them by collective action [16].

\subsection{Sources of Self Efficacy}

Consistent with social cognitive theory, the major influences on efficacy beliefs are assumed to be the attributional analysis and interpretation of the four sources of information about efficacy described by Bandura [16]. Efficacy beliefs (through cognitive, affective, and motivational regulatory mechanisms) influence how people feel, how much effort they invest in actions, how long they persevere in the face of obstacles and failures, and how resilient they are to adversity. Efficacious people are quick to take advantage of opportunity structures and figure out ways to circumvent institutional constraints or change them by collective action [16]. Self efficacy 
has then an impact on a variety of domains and behaviours and affects how one act in a personal and professional level. The more one believes in their own capabilities, the greater will be one's satisfaction [19].

Enactive mastery experiences that serve as indicators of capability. The most effective way of developing a strong sense of efficacy is through mastery experiences, Bandura explained (1994). Performing a task successfully strengthens people’s sense of self-efficacy. On the other hand, failing to adequately carry out with a task or challenge can have a negative impact on and weaken self-efficacy.

Vicarious experiences that alter efficacy beliefs through transmission of competencies and comparison with the attainments of others. Witnessing others successfully completing a task is another important source of self-efficacy. According to Bandura, "Seeing people similar to oneself succeed by sustained effort raises observers' beliefs that they too possess the capabilities master comparable activities to succeed" [14].

Verbal persuasion and allied types of social influences that one possesses certain capabilities. Bandura also asserted that people could in fact be persuaded to believe that they have the skills and capabilities to succeed. Contemplating on an occasion when someone said something positive and encouraging that encouraged a person to complete a task or getting positive feedback and verbal encouragement from others helps people overcome their self-doubts and instead focus on putting their best effort on a task or action. The impact of verbal persuasion on self-efficacy may vary substantially depending on the perceived credibility of the persuaders, their prestige, trustworthiness, expertise and assuredness [16].

Psychological and affective states from which people partly judge their capableness, strength and vulnerability to dysfunction. People's responses and emotional reactions to situations also play an important role in developing a sense of self-efficacy. Psychological, physiological and emotional states, situational circumstances and stress levels can all impact how a person feels about their personal abilities under certain circumstance. A person who becomes extremely nervous before beginning a task, a teacher before entering the classroom for instance, may develop a weak sense of self-efficacy in these situations. However, Bandura (1994) [14] also comments that it is not the sheer intensity of emotional and physical reactions that is important but rather how they are perceived and interpreted. By learning how to cope with and eliminate stress and improve their emotional state when facing difficult or challenging tasks, people can improve their sense of self-efficacy.

Looking at the Learning through Modeling as discussed above the, the factors that contribute to learning are very similar to the sources that develop self efficacy beliefs. There are several processes by which modeling exerts its effects on efficacy beliefs [16]. Observation plays a major role in both learning new behaviours and developing capabilities. Also, the feedback following the actions is a contributor as well as very importantly the way each individual processes the information and the quality of their behaviour and task which then inform future actions. People not only experience the results of their efforts but also see how other are faring in similar circumstances and occasionally receive social evaluations of the adequacy of their performance [16]. Through social comparative inference, the attainments of others who are similar to oneself are judged to be diagnostic of one's capabilities [16]. The different forms of efficacy influences rarely operate separately and independently.

According to social cognitive theorists people's feelings of self efficacy affect several aspects of their behaviour, including their choice of activities, their goals, their effort and persistence, and ultimately the quality of their performance and their learning. Perceived self-efficacy influences the level of goal challenge people set for themselves, the amount of effort they mobilize, and their persistence in the face of difficulties. Perceived self-efficacy is theorized to influence performance accomplishments both directly and indirectly [52]. Self Efficacy Affects i) Choice of activities Individuals tend to select tasks and activities in which they feel competent and confident and avoid those in which they do not [39].ii)Goals Perceived self-efficacy influences the level of goal challenge people set for themselves [52]. Selfregulated learners direct their learning processes and attainments by setting challenging goals for themselves [13]. Self-regulated learners exhibit a high sense of efficacy in their capabilities, which influences the knowledge and skill goals they set for themselves and their commitment to fulfill these challenges [52]. According to social cognitive theory (Bandura, 1986 goals increase people's cognitive and affective reactions to performance outcomes because goals specify the requirements for personal success iii)Effort and persistence Perceived self-efficacy influences the amount of effort they mobilize [52].The higher the sense of efficacy, the greater the effort, persistence, and resilience. People with a strong sense of personal competence approach difficult tasks as challenges to be mastered rather than as threats to be avoided [39]. iv) Quality of individual performance. Perceived self-efficacy is theorized toinfluence performance accomplishments both directly and indirectly [52]. High self-efficacy helps create feelings of serenity in approaching difficult tasks and activities. Conversely, people with low self-efficacy may believe that things are tougher than they really are, a belief that fosters anxiety, stress, depression, and a 
narrow vision of how best to solve a problem. As a consequence, self-efficacy beliefs can powerfully influence the level of accomplishment that one ultimately achieves [39].

\section{Teachers’ Efficacy}

Teachers' efficacy research, historically, began with the RAND Corporation studies in 1976. Rand researchers examined teacher characteristics, the change process, teacher growth and student learning.

The task of creating learning environments conducive to development of cognitive skills rests heavily on the talents and self-efficacy of teachers. Those who are well-versed in their subject matter and have a high sense of efficacy about their teaching capabilities can motivate low achievers and enhance their cognitive development [3],[23]. The staffs of successful schools, whether they serve predominantly advantaged or disadvantaged students, have a strong group sense of efficacy to fulfill their academic purpose and resiliency of perceived efficacy in the face of social realities strewn with frustrations [33].

Coladarci and Breton (1997) [21] examined the relationship between supervisory visits to the classrooms of teachers assigned to resource room positions. They found that the perceived usefulness of supervisory visits and not the number of visits each year had greater predictive value for teacher efficacy. They also determined that women and older teachers (even those with less experience in the resource room setting) reported higher levels of efficacy than men and younger teachers.

Teachers' efficacy has proven to be an important variable in teacher effectiveness. Research also provides evidence that it is also linked to student attainment. Low teacher efficacy leads to low student efficacy and low academic achievement, which in turn leads to further declines in teacher efficacy [16]. It has been defined as “teachers' belief or conviction that they can influence how well students learn, even those who may be considered difficult or unmotivated" [29 p. 628]. The more committed a teacher was to the underlying philosophy of a teaching orientation, the greater the sense that he or she was having an effect on students. This indicates that the more one understands and adheres to a theoretical orientation, the more effective one feels as a teacher [30].

Teachers' self-efficacy beliefs (high internal locus of control and positive attitude to-ward overcoming difficult situations) have been linked to their classroom behaviour and [3]. Some teachers feel more efficacious and hold more positive attitudes toward teaching than others [41]. Teachers who believe strongly in their efficacy tend to be open new ideas, more willing to try new methods, more committed to teaching, more resilient to difficulties in work conditions, and tend to be less critical of students who make errors [3], [21], [23], [49].

Viel-Ruma et. al [50] surveyed 104 special educators and found that teacher self-efficacy had a direct effect on job satisfaction. It was further found that collective efficacy directly affected teacher self efficacy but that it did not have a direct effect on job satisfaction. No significant differences were found in reported levels of these areas across subgroups of teachers categorized by teaching level (elementary, middle, and high), teaching setting (self-contained, resource, or inclusion), andcertification type (highly qualified, not highly qualified, or emergency).

\subsection{General and Personal Teacher Efficacy}

Ashton and Webb [3] suggested two independent dimensions of teacher efficacy. They claimed that teacher's outcome expectations about the consequences of their teaching in general is called teaching efficacy. Additionally, they named personal efficacy as teacher's personal ability to execute specific actions to achieve desired results. Tschannen-Moran, and Hoy [49] argue that teaching Efficacy can be either personal teaching efficacy (PTE); it is more specific and individual or (general) Teaching efficacy (GTE). Personal efficacy is the equivalent to Bandura's efficacy expectation, is that teachers' belief in their ability to bring about change in students. Teaching efficacy, the equivalent to Bandura's outcome expectation, is the teachers' belief that students can be taught despite external factors, such as their family environment [23]. A belief about what teachers in general can accomplish teacher efficacy (TE), a construct that purported to reveal the extent to which a teacher believed that the consequences of teaching-student motivation and learning-were in the hands of the teacher, that is, internally controlled.

The construct of teachers' efficacy has been divided into two sub categories; general teacher efficacy and personal teacher efficacy. These two dimensions of efficacy can operate independently; while general teacher efficacy considers factors external to the classroom such as social and environmental, personal teacher efficacy maintains a degree of focus on individual's perception at the level of individualistic characteristics [3], [21], [23], [49].

Studies Ashton et al. [3] and mpre contemporary work has suggested that school organization (principal influence, colleague support, resource support, academic emphasis) help teacher accomplish their goals and may also help improve teacher efficacy. Because self efficacy beliefs influences the selections of activities and environments, teachers are not supported by the school organization may feel low self efficacious and leave their profession. 
Efficacious teachers devise and modify instructional strategies to meet students' needs. They spend more time monitoring and facilitating seatwork, and providing whole group instruction [23]. They are more willing to learn and try out new approaches and strategies to meet students' needs [29], [42]. They continually look for ways to help students overcome learning problems. Teachers who succeed in reaching low achieving students combine a strong sense of efficacy with high and realistic expectations for student achievement [1]. They help students to set attainable goals [42]. They not only communicate expectations that their students will achieve but ensure that students are taught the necessary skills and learning strategies [1].

A small number of self-efficacy studies related to teachers of students with disabilities have emerged in recent years. Paneque and Barbetta [40] surveyed 202 special education teachers and the results revealed that overall, the special education teacher efficacy scores in this study were high. The same outcome is supported by the study of Carlson et.al [20] who employed teachers for students with special needs. In regards to the section on self-efficacy, they found that overall special education teachers reported high efficacy A study investigating the sources of self-efficacy among teachers of students with autism (Ruble et.al, 2011); revealed Significant associations between physiological/affective states and selfefficacy, but no associations were observed for the other sources. Allinder [2] found that special education teachers who reported higher levels of self-efficacy were more likely to be organized and likely to engage in instructional planning.

Most studies involving efficacy and special education teachers have focused on attrition and burnout. The results of a recent study by Viel-Ruma et. al [50] indicated that teacher self-efficacy had a direct effect on job satisfaction. It was further found that collective efficacy directly affected teacher self efficacy but that it did not have a direct effect on job satisfaction. No significant differences were found in reported levels of these areas across subgroups of teachers categorized by teaching level (elementary, middle, and high), teaching setting (self-contained, resource, or inclusion), and certification type (highly qualified, not highly qualified, or emergency).

Jennett et. al, [30] found that the relationship between a commitment to one's teaching approach and certain dimensions of teaching efficacy and burnout was found to be significant. Implications include the need for adequate training of teachers of students with autism. Although all teachers experience stress, additional stressors exist for special education teachers [30]. Although all special education teachers are potentially at risk for burnout because of the challenging nature of their students, teachers of students with autism may be especially at risk [30]. This is one of the very few studies on teachers for children with Autism. The groups included who work with students with autism in one of two widely used treatment approaches for autism: Applied Behavior Analysis (ABA) and TEACCH (Treatment and Education of Autistic and Related Communication Handicapped Children). The results revealed that for both groups, the commitment score was significantlycorrelated with the Personal Efficacy dimension of teaching efficacy such that the higher the commitment score the higher the sense of personal efficacy. Also, for both groups, the commitment score was significantly correlated with the Personal Efficacy dimension of teaching efficacy such that the higher the commitment score the higher the sense of personal efficacy. The groups differed neither on their level of personal efficacy nor on their level of general efficacy.

Yeo et. al [51] studied Singapore teachers for low achieving student and found significant differences between novice teachers and experienced teachers emerged in teacher efficacy beliefs in relation to instructional strategies, classroom management, and student engagement. Higher efficacy was reported as they matured in their years of professional experience. Highly experienced teachers who had more than fifteen years' teaching experience had a stronger sense of efficacy in providing instructional strategies and engaging students compared to novice teachers who had less than five years' teaching experience. No significant differences at were found for all three dimensions of teacher efficacy against the independent variables of gender and number of levels taught. However, analysis indicated significant differences in teacher efficacy in relation to years of professional experience for instructional strategies; classroom management, and student engagement. Significant differences in teacher efficacy were found in only the dimension of classroom management in relation to teachers' age.

\section{Collective Efficacy}

Collective efficacy refers to the perceived "performance capability of a social system as a whole" [16]. Based on social cognitive theory, Bandura [10],[14],[16] expanded the construct of self-efficacy to the larger, social construct of collective efficacy within group settings. Schools are large group settings and teaching cannot occur in isolation. Beliefs of collective efficacy serve functions similar to those of personal efficacy beliefs and operate through similar processes [16].

Personal agency operates within a broad network of socio structural influences" ([16]p. 6) and thus the theory "extends the analysis of mechanisms of human agency to the exercise of collective agency" [16 p.7].Collective efficacy refers to people's shared beliefs that they can work together to produce effects [27].The concept of collective efficacy is similar to 
self-efficacy in that it focuses on the amount of effort and persistence dedicated to a task and the perception of the success of that task [16].Collective efficacy is likely related to self-efficacy since the perceived sense of group efficacy is related to the individual perceived efficacy of the members of the group [16].

Because the collective performance of a social system involves transactional dynamics, perceived collective efficacy is an emergent group-level property, not simply the sum of the efficacy beliefs of individual members [17].The stronger the perceived collective efficacy, the higher the groups' aspirations and motivational investment in their undertakings, the stronger their staying power in the face of impediments and setbacks, the higher their morale and resilience to stressors, and the greater their performance accomplishments [17].

People's shared belief in their collective power to produce desired results is a key ingredient of collective agency. Group attainments are the product not only of the shared intentions, knowledge, and skills of its members, but also of the interactive, coordinated, and synergistic dynamics of their transactions [17].Collective agentic adaptability applies at the organizational level as well as the workforce level. Organizations have to be fast learners and continuously innovative to survive and prosper under rapidly changing technologies and global marketplaces [17].

\subsection{Teachers' Collective Efficacy}

While teachers' self-efficacy has been studied in some depth, the concept of collective efficacy has received lower attention [37]. The concept of collective efficacy has been examined less frequently in relatively few studies [37]. Collective teacher efficacy refers to teachers' belief about the collective capability of a group of teachers to influence student achievement [28]. Teacher collective efficacy was measured by teachers' perceptions of school collective efficacy rather than the "schools' sense of collective efficacy as an aggregate of teachers' group-referent efficacy perceptions” [27 p.7 $]$. Bandura [13] summed the teachers' beliefs about their school's capacity to promote different levels of academic attainment. He found that teachers' belief in the school's efficacy as a whole was just as predictive of school performance as teachers' beliefs in their own efficacy. Skaalvik and Skaalvik [47] suggested that one should attempt raise teachers competencies collectively through school development.

Research has shown that teachers' self-efficacy beliefs influence the achievement of those teachers' students; and at the school level, the collective perception of teacher efficacy in the building also influence how well all students in that particular school perform [14], [16]. Teachers work together to accomplish an established goal in educating children. Pajares [36], [37] also drew from social cognitive theory and agreed upon the collective process of education

Bandura [14] himself demonstrated a positive effect of collective efficacy and student achievement regardless of socioeconomic status, race, or ethnicity of students. Series of research followed examining the relationship between collective efficacy and student achievement [24], [25],[26],[27]. Goddard, Hoy, and Woolfolk-Hoy (2000) [24] did find a significant relationship between schools' student achievement and collective efficacy levels.

The assumption is that when teachers as a group in school believe that the staff as a whole can be successful, they will be more likely to persist in their own personal efforts to achieve such success [25].

Collective efficacy for special educators has received less research interest compared to self efficacy. Viel- Ruma et.al [50] found that a significant relationship between job satisfaction and teacher self-efficacy. Furthermore, a significant relationship between teacher self-efficacy and collective efficacy was found. However, a significant relationship between collective efficacy and job satisfaction was not detected.

\section{Objectives}

This study seeks to shed light on teachers' self efficacy and collective efficacy beliefs of their capabilities in teaching children with autism in schools across the UK. This study will look into the concept of self efficacy in regards to instructional practices, professionalism, teacher support, classroom management and related duties. The study will seek to establish relationships between self efficacy and collective efficacy beliefs.

Demographic and biographic information acquired will explore relationships between the two constructs and teachers/schools information in regards to their teaching experience, training, teaching methods and students' attainment. Teachers from 137 schools for children with autism across UK will be asked to complete an online survey consisting of three questionnaires on demographics, self efficacy and collective efficacy beliefs.

The following issues will be investigated in detail: Teachers' Self - Efficacy (SE) beliefs in relation to: Instruction, Professionalism, Teacher Support, Classroom Management, Related Duties. Teachers' Collective - Efficacy (CE) beliefs in relation to: Instruction, Student discipline. Teacher's Demographic/biographic Information, Years of experience in autism context, qualifications/training and teaching methods. Analysis will seek for correlations between SE and CE, SE and demographic factors, CE and Demographic factors. 
The rationale for undertaking such a study in the UK served a number of purposes. First, teacher efficacy for autism educators is an area that has not been widely researched in Europe although it has received some attention in America.

In the UK, the research on teacher efficacy is extremely sparse and very little is known about how teachers for children with autism perceive their ability to teach. Second, to the best of our knowledge, hitherto, the Tschannen-Moran et al.'s [49] concept of teacher efficacy has not been examined in the UK, and it is interesting to ascertain its applicability to a population of UK teachers for children with autism. Third, though much has been written about teacher efficacy, the literature is comparatively reticent on how teacher efficacy is understood in the context of teaching children with autism. Hence, the present study seeks to understand the self efficacy of teachers for children with autism in the UK and to explore the major factors that influence teacher efficacy where it relates to students who have autism. Lastly, the area of collective efficacy for teachers for children with autism in the UK has received very limited, if any attention as far as our literature review reveals.

\section{Methods}

Methodology refers to the 'theory of getting knowledge, to the consideration of the best ways, methods or procedures, by which data will provide the evidence basis for the construction of knowledge about whatever it is that is being researched, is obtained' [34]. The gathering of date will take place in two stages. During the first stage online questionnaires will be distributed to all schools for children with autism in the UK. The first stage is already in process and data is being gathered. After the responses have been gathered, a number of the participants who have completed the online survey will be then interviewed to gain more understanding. The selection of the interviewees will depend of the responses of a certain school and the themes that will arise.

\section{Participants}

The study is based in UK schools for Children with Autism. The list of participating was drawn from the National Autistic Society (NAS) school database and from data from the Department of Education, which produced 137 results. The participants will consist of an opportunity sample of teachers of these schools. Schools will be identified and consent will be requested by the Head Teachers. The study is supported by the National Autistic Society. The study is being advertised on their website and request for participants has been sent to schools.

\section{Instruments}

Three questionnaires will be used to collect data: Q1: Demographic information -12 multiple choice question, Q2: Self -Efficacy, 30 item, 9 points Likert Scale (adapted from Dawson, 2010), Q3: Collective Efficacy, 12 item, 9 points Likert Scale (adapted from Tschannen-Moran, Barr, [49]) The questionnaires will be in the form of an online survey. A brief description of the aims of the study will be provided as well as a statement about the anonymity and the protection of personal data of the participants.

\section{Contribution to Research}

This study will provide an insight into autism teachers' for children with autism self efficacy and collective efficacy beliefs. Since the 1970s most studies have explored mainstream environments. A review of Klassen [32] of the efficacy research revealed that only $7 \%$ of the results examined collective efficacy. There is also a need to expand efficacy research further into special education and autism in particular where the results are currently very limited.

Educating children with autism is very much based on a team effort. Teachers work in collaboration with teaching assistants and other specialist professionals. It is therefore important to look into the beliefs teachers have of the group's / schools' capability to provide effective teaching.

The information gathered will be useful to the schools and policy makers for future planning and curriculum development. As SE and CE are closely related to student attainment, this study will reveal possible links and provide ground for future research on the sources and development of SE and CE.

\section{Conclusion}

The present study is still in process and there are no conclusions based on data at this stage. However, what has become apparent form the literature is the lack of strong evidence to support self efficacy and collective efficacy of teachers and teachers for children with autism in the UK.

\section{References}

[1] M. K. Alderman, "Motivation for at-risk students”, Educational Leadership, 1990, 48, pp. 27-30.

[2] R.M. Allinder, "The relationship between efficacy and the instructional practices of special education teachers and consultants". Teacher Education and Special Education, 1994, 17, pp.86- 
95.

[3] P. T. Ashton, R. B. Webb, Teachers' sense of efficacy: Toward an ecological model. Paper presented at the annual meeting of the American Educational Research, March, 1982.

[4] P. T. Ashton, R. Webb, N. Doda, A study of teachers' sense of efficacy, ERIC Document Reproduction Service no. ED231834, 1983.

[5] A. Bandura, R. H. Walters, Social Learning and Personality Development, New York: Holt, Rinehart, Winston, 1963.

[6] A. Bandura, Social foundations of thought and action: A social cognitive theory, Englewood Cliffs, NJ: Prentice Hall.Association, New York, 1986.

[7] A. Bandura, "Exercise of personal agency through the self-efficacy mechanisms", In R. Schwarzer (Ed.), Self-efficacy: Thought control of action. Washington, DC: Hemisphere, 1992.

[8] A.Bandura, "The role of imitation in personality development”, The Journal of Nursery Education, 1963.

[9] A.Bandura, R. Walters, Social learning and personality development, New York: Holt, Rinehart and Winston , 1963.

[10] A. Bandura, Social foundations of thought and action: A social cognitive theory, Englewood Cliffs, NJ: Prentice Hall, 1986.

[11] A.Bandura, "Self-efficacy: Toward a unifying theory of behavioral change”, Psychological Review, 1977b, 84, pp. 191-215.

[12] A.Bandura, Social learning theory, Englewood Cliffs, NJ: Prentice Hall, 1977.

[13] Bandura, (1989) “Social cognitive theory”, in R. Vasta (Ed.), Annals of child development. Vol. 6. Theories of Child Development (1-60). Greenwich, CT: JAI Press.

[14] Bandura, "Self-efficacy”, In V. S. Ramachaudran (Ed.), Encyclopedia of human behavior, Vol. 4. New York: Academic Press, 1994, pp. 71-81.

[15] Bandura, Self-Efficacy in Changing Societies. Cambridge University Press, 1995.

[16] Bandura, Self-efficacy: The exercise of control. New York: Freeman, 1997.
[17] Bandura, "Social cognitive theory: An agentic perspective”, Annual Review of Psychology, 2001, 52, pp. 1-26.

[18] J. Brophy, J \& C. Evertson, Learning from teaching: A developmental perspective, Boston: Allyn \&Bacon, 1976.

[19] G. V. Caprara, C. Barbaranelli, L. Borgogni, P. Steca, "Efficacy beliefs as determinants of teachers' job satisfaction”, Journal of Educational Psychology, 2003, 95, pp. 821-832.

[20] E. Carlson, H. Lee, K. Schroll, S. Klein, S. Willing "Final Report of the Study of Personnel Needs in Special Education”.Washington, DC: Office of Special Education Programs, U.S. Department of Education, 2002.

[21] T. Coladarci, W.Breton, “Teacher efficacy, supervision, and the special education resource-room teacher”. Journal of Educational Research, 1997, 90, 230-239.

[22] K. Crawford, "Vygotskian approaches to human development in the information era", Educational Studies in Mathematics, 1996, 31, pp. 43-62.

[23] S. Gibson, M. Dembo.” Teacher efficacy: A construct validation", Journal of Educational Psychology, 1984, 76(4), pp. 569-582.

[24] R. D. Goddard, W. K. Hoy, A. W. Hoy, "Collective efficacy: Its meaning, measure, and impact on student achievement”, American Education Research Journal, 2000, 37, pp. 479-507.

[25] R. D. Goddard, “Collective efficacy: A neglected construct in the study of schoolsand student achievement”, Journal of Educational Psychology, 2001, 93(3), pp. 467-476.

[26] R. D Goddard, Y. L. Goddard, “A multi level analysis of the relationship between teacher and collective efficacy in urban schools". Teacher and Teacher Education, 2001, 17, pp. 807-818.

[27] R. D. Goddard, W. K. Hoy, A. Woolfolk Hoy, "Collective efficacy beliefs:theoretical developments, empirical evidence, and future directions”. Educational Researcher, 2004, 33, pp. 313.

[28] D. Goddard, L. LoGerfo, W. K. Hoy, "High school accountability: The role of perceived efficacy”. Educational Policy, 2004b, 18, pp. 403425.

[29] R. Guskey, “Teacher efficacy, self-concept, and 
attitudes toward the implementation of instructional innovation”. Teaching and Teacher Education, 1988, 4, pp. 63-69.

[30] H. K. Jennett, S. L. Harris, G. B. Mesibov, "Commitment to philosophy, teacher efficacy, and burnout among teachers of children with autism”. Journal of Autism and Developmental Disorders, 2003, 33, pp. 583-593R.

[31] P. Howlin, "Psychological and Educational Treatments for Autism”, Journal of Child Psychology and Psychiatry, 1998, 39(3), pp. 30722.

[32] R.M. Klassen, V. Tze, K. Gordon and, S. Betts, "Teacher efficacy research 1998-2009: Signs of progress or unfulfilled promise?” Educational Psychology Review, 2011, 23, pp. 21-43.

[33] L. Lightfoot,."The Lives of Teachers," in The Handbook of Teachers and Policy [Eds. Lee Shulman and Gary Sykes], New York: Longman, Inc., 1983.

[34] Opie, Doing Educational Research, Paul Chapman Publishing, London, 2004.

[35] S. Padeliadu, G. Chatzopoulos, E. Kavvada, “Teachers'Stereotypes Regarding the Learning Abilities of Students with Mental Retardation”,paper presented at the International Conference on Developmental/Intellectual Disabilities 'Bridging the Continents’, Larnaca, Cyprus, 27-9 March, 1998.

[36] F. Pajares, "Self-efficacy beliefs in academic settings”. Review of Educational Research, 1996, 66(4), pp. 543-578.

[37] F. Pajares, "Current directions in self-efficacy research”. In Maehr and P. R. Pintrich (Eds.), Advances in Motivation and Achievement, Greenwich, CT: JAI Press, 1997, pp. 1-49

[38] F. Pajares, D. H Schunk, "Self-beliefs and school success: Self-efficacy, self-concept, and school achievement”. In R. Riding \& S. Rayner (Eds.), Self-perception, London: Ablex Publishing, 2001, pp. 239-266

[39] F. Pajares, Overview of social cognitive theory and of self-efficacy.

http://www.emory.edu/EDUCATION/mfp/eff .html, 2002, (Access date: 20 December 2011).

[40] O. M., Paneque, P. M. Barbetta,“A study of teacher e fficacy of special education teachers of English langu age learners with disabilities”. Bilingual Research Jo urnal, 2006, 30, pp.171-193.

[41] S. E. Rimm-Kaufman, B. E. Sawyer, "Primarygrade teachers' self-efficacy beliefs, attitudes toward teaching, and discipline and teaching practice priorities in relation to the responsive classroom approach”. Elementary School Journal, 2004, pp. 104-321.

[42] J. A. Ross, "The antecedents and consequences of teacher efficacy”. In J. Brophy (Ed.), Advances in research on teaching, vol. 7, Greenwich: JAI, 1998, pp. 49-73

[43] J. A. Ross, P. Gray, “Transformational leadership and teacher commitment to organizational values: The mediating effects of collective teacher efficacy”. School Effectiveness and School Improvement, 2006, 17(2), pp. 179-199.

[44] L. A. Ruble, E. L. Usher, J. McGrew, "Special education and students with autism: Preliminary investigation of teacher self-efficacy and its sources”. Focus on Autism and Other Developmental Disabilities, 2011, 26(2), pp. 67-74.

[45] Scheuermann, J. Webber, E. A. Boutot, and M. Goodwin, "Problems with personnel preparation in autism spectrum disorders", Focus on Autism and Other Developmental Disabilities, 2003, 18, pp. 197-206.

[46] H. Schunk, F. Pajares, “The development of academic self-efficacy”. In A. Wigfield \& J. Eccles (Eds.), Development of achievement motivation. San Diego: Academic Press, 2002, pp. 16-31

[47] M. Skaalvik, S. Skaalvik, "Dimensions of teacher self-efficacy and relations with strain factors, perceived collective teacher efficacy, and teacher burnout”. Journal of Educational Psychology, 2007, 99, pp. 611-625.

[48] Skinner, The Behavior of Organisms: An Experimental Analysis. New York: AppletonCentury, 1938

[49] M. Tschannen-Moran, A. W. Hoy, W. K. Hoy, "Teacher efficacy: Its meaning and measure". Review of Educational Research, 1998, 68, pp. 202248.

[50] K. Viel-Ruma, D. Houchins, K. Jolivette, K. Benson, "Efficacy beliefs of special educators : The relationships among collective efficacy, teacher selfeffícacy , and job satisfaction”. Teacher Education and Special Education, Volume: 33, 2010. 
[51] L.S. Yeo, R P. Ang, W.H. Chong, V.S. Huan, C.

L. Quek, "Teacher Efficacy In the Context of Teaching Low Achieving Students", Current Psychology; 2008, Vol. 27 Issue 3, p. 192-204.

[52] J. Zimmerman, A. Bandura, M. Martinez-Pons, "Self-motivation for academic attainment: The role of self-efficacy beliefs and personal goal setting". American Educational Research Journal, 1992, 29, pp. 663-676. 